\title{
AN EXAMINATION OF THE IMPACT OF ETHICAL LEADERSHIP ON INDIVIDUAL CREATIVITY AND ORGANIZATIONAL INNOVATIONS IN THE ICT INDUSTRY IN VIETNAM
}

Anantha Raj A. Arokiasamy ${ }^{*}$, Massoud Moslehpour ${ }^{2}$

${ }^{1 *}$ RMIT International University, School of Business and Management, Ho Chi Minh City, Vietnam; ${ }^{2}$ Asia University, Department of Business Administration, Taichung, Taiwan.

Email: ${ }^{*}$ anantharaj.arokiasamy@ rmit.edu.vn, ${ }^{2}$ writetodrm@gmail.com

Article History: Received on $13^{\text {th }}$ May 2021, Revised on 20 ${ }^{\text {th }}$ May 2021, Published on $26^{\text {th }}$ May 2021

Abstract

Purpose of the study: In the present study, information was obtained from 245 Information and Communication Technology (ICT) organizations from Vietnam using a market-oriented criterion to assess individual creativity, ethical leadership, and organizational innovation.

Methodology: The absolute, as well as intended influences of ethical leaderships over the creativities along with innovations, were investigated using modelling that is multilevel plus tiered regressions analysis. We also tested the direct and indirect effects of ethical leadership on creativity and innovation using multilevel modelling and hierarchical regression analyses, respectively.

Main Findings: The results showed ethical leadership is a strong indicator of both human and organizational imagination. On the corporate levels, observations suggest that ethical leadership remains closely correlated with organizational innovations. The results also suggest that ethical leadership is an essential method for promoting entrepreneurship and advancing growth in both emerging countries and newly developed industries.

Applications of this study: On the corporate levels, observations suggest that ethical leadership remains closely correlated with organizational innovations.

Novelty/Originality of this study: The study's key part remains essentially to examine creativity as a possible intermediary in favour of the ethical leadership's organizational interconnections, in which a markets-focused standard is used as a surrogate for innovations at the organizational level.

Keywords: Ethical Leadership, Organizational Innovations, Individual Creativity, Vietnam.

\section{INTRODUCTION}

Revolutions have for a very long time been considered particularly the most critical drivers in a company's progress and a country's economic growth. As a result, academics have often placed a greater focus on recognizing the conditions that promote or hinder innovation practices in organizational settings. The recent period, marked by an increasingly volatile business climate, globalization, accelerated technological advances, and shortened product life cycles, has placed companies under pressure to consistently discovering novel methods of accomplishing activities as well as creative offers to maintain a sustainable place in the industry. Effective creativity, on the other hand, is based on several human and organizational-level variables (Hon \& Lui, 2016). A few scholarships, for example, have identified creativities for the generation of constructive along with original ideas like a prerequisite aimed at innovations, the efficient implementation of inventive ideas within business. Various analyses further had focused on the function of different leadership approaches for enhancing innovation efficiency (Yuen \& Balakrishnan, 2019). Despite the presence of multiple research over the association amid various approaches of leadership, imagination, as well as organizational innovations, the current area of study remains unevolved.

Leadership happens to be identified as a significant foundation to foster entrepreneurship, also like a significant factor for innovations that are on the firm-levels in previous studies. Locke et al. (2019), for example, investigated linkage patterns linking the innovatory leadership approach as well as innovations that are at a level of organization through an individual's level of imagination. In another analysis, Acar et al. (2019) used a multilevel model to investigate the impact of authentic leadership over the team's inventiveness through creativity on the individual's level. Caniëls and Rietzschel (2015) presented the effect relating to servant leaderships over human creativeness as well as growth using results from 154 teams. According to new research, ethical leadership fosters individuals' innovation. With growing questions about corporate ethics, it is important to consider how leaders can improve employee innovation through ethical activities, in addition to the effect relating to principled leadership methods over the results of the organization. As a result, the current study aims to investigate in what way ethical leadership affects executive creativeness along with organizational innovations. 
Ethical leads engage in normatively acceptable ethical practices and express these behaviors through their deeds. Such leaders raise their workers' expectations and aim to transform their workers' distinctiveness along with professional values up to a higher level of priorities as well as desires. As a result, ethical leaders have a profound impact on work preferences (for example, the satisfaction of job) plus actions namely, behavior of voice, spiritual identification, also corporate citizenships manner. The previous study has traditionally connected leadership's that are ethical towards supporters' ethical as well as unethical behavior, plus lesser consideration have been given to contributing links amidst ethical headship, employee innovation, and organization's effectiveness. Their hire-hands, on the other hand, frequently confront varieties of obstacles as well as ethical quandaries when creating as well as introducing novel innovations, emphasizing the importance of ethical heads that uphold ethical principles, responsibilities of oneself and autonomy towards work as future interpreters relating to innovative activities as well as inventive results (Valaei et al., 2017). As a result, the primary aim of this thesis is to learn about the effect of ethical leadership over creativeness along with corporate revolution via fostering the creativity of this kind.

Firstly, current research is based on the upper echelon's hypothesis, which proposes that the traits of leaders influence organizational participants' view of their world. As a result, we argue that one's perception of the working atmosphere is a significant determinant of one's imagination since a visible environment of the workplace influences person's psychosomatic meaning as well as nurtures a person's motivation for generating fresh ideas. Because of leadership that is ethical, in the sense of the workplace, we argue for ethical leadership being probable for improving worker information exchange, native engagement, as well as relational empowerments that encourage employee's creativeness, also facilitate organizational modernizations. Provided that ethical heads being crucial components in motivating as well as empowering workers belonging to them for producing effective working results (Ghosh, 2015), our team believes in ethical leaderships being required for fostering an ambitious atmosphere as well as inspire employees for participating in imaginative thinking. While previous research looked at empowerment of employees as a catalyst for worker practices namely success of the employee and organizational citizenship behavior from an ethical leadership standpoint, innovation was left out (Oliver et al., 2019). According to the current research, the fundamental factor that describes the influence of ethical leadership over revolution is the relational encouragement of workers, along with inherent inspiration and information sharing.

Second, emerging ethical leadership research struggles to offer a specific discernment of the possible function it to promote corporate creativity. Juxtaposing to another leadership's models as well as stable results, current research over leadership that is ethical emphases over limited facets of firm levels results in namely credibility that is firm (Caniëls \& Rietzschel, 2013), firm success, systemic transformation, corporate social responsibility, and organizational innovativeness. The viewpoint of innovations that are organization related is unanswered, besides having an exception of Millet et al. (2017) work, which is the lone research to self-erudition which explored the impact of ethical leadership over the inventiveness relating to the organization (capacity to firmly transform) within Lithuanian sense as well as discovered ethical leaderships to be one of the effective interpreters to the creativeness. Nevertheless, Millet et al. (2017) solely measured the potential of a firm besides innovation's proclivity, instead of real revolution results, such as effectiveness in innovation. Moreover, the listed study was conducted within the western context, plus the respondents belonged from a particularly sole corporation, restricting comprehension on the role of ethical leadership within contexts that is eastern through various first. For packing such hole, the current study indicates ethical leaderships to be successful to foster managerial creativity within the eastern sense. Our team invoked corporate creativity like "the organization's tendency to produce new or better products/services and its performance in getting such products/services to market," thereby capturing two essential facets of innovation: a proclivity for innovating as well as innovation's achievements. Our team concludes that, in addition to a lack of literature, innovations relating to the organization remain the result of innovative efforts along with successes within the organization, therefore investigating the functions relating to ethical leaderships, is similarly necessary aimed at innovations relating to the organization. As a result, this analysis aims to look at the effect of ethical leadership over employee creativeness besides innovations relating to the organization.

As per the intended investigation paradigm, there is an absolute as well as unintended influence on the ethical leaderships over employee creativeness through inherent inspiration, information distribution, along with empowerments that are relational. Ethical leadership along with individual's creativeness encourages organizational innovations (demonstrated in Figure 1).

\section{LITERATURE REVIEW}

\section{Ethical leadership and Employee Creativity}

Ethical headship is described as "the display of normatively acceptable behavior through personal acts and interpersonal relationships, as well as the encouragement of such behavior to followers through two-way contact, reinforcement, and decision-making (Feng et al., 2018)." Ethical leaders display qualities such as dignity, caring, transparency, fairness, trustworthiness, altruism, justice as well as mutual inspiration that empowers to make them impartial as well as decent 
decisions. Furthermore, ethical leaders influence workers' imagination through cognition and inspiration. Heads having strong moral as well as ethical significance are shown to be encouragingly stimulating employee's perception by stressing role relating to the work of employee to achieve organizational objectives (Duan et al., 2018). Thus, the perception process inspires the workers for paying greater attentiveness to the importance of self jobs, contributing them to the development and implementation of novel strategies to discover new approaches to accomplish corporate goals. Furthermore, ethical leaders consider their staff and encourage them to share their questions and ideas through dyadic open dialogue, which creates trust. Furthermore, open collaboration encourages workers to use their creativity to generate fresh ideas for improving current job procedures. The motivational process is related to confirming that ethical heads subsist valued through one's supporters relating to their growth as well as integrity, allowing workers to acquire new skills and expertise relevant to their employment (Asif et al., 2020). As a result, it would increase workforce efficacy, encouraging workers to do their jobs creatively.

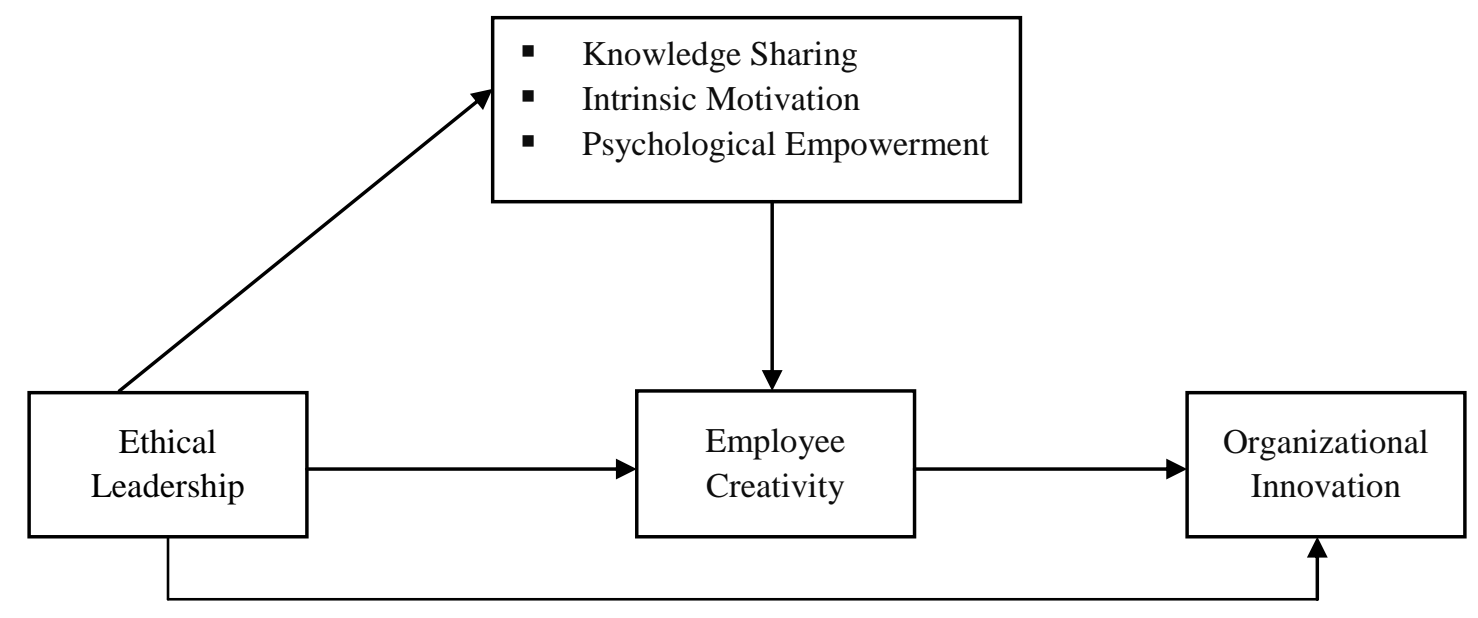

Figure 1: Proposed Conceptual Framework

Furthermore, ethical heads remain oriented to people plus remain more inclined towards encouraging equal privileges, sense of worth, abilities, as well as erudition via presenting workers various means of opportunity for learning job-related skills and experience and putting them in suitable roles. They also inspire followers to guide their talents in the right way for better job success, and as a result, workers will gain the expertise, experience, and desire to practice innovatively, and would likely implement an imaginative mindset within the workplace that will improve innovation of them (Ma et al., 2013). Moreover, the higher grade viewpoint aids in explaining the relationship between leader and follower in the way in which ethical heads offer admirers through considerable freedom as well as influence on conclusion making in place of work, ensuring selfsufficiency, independence, as well as determination over careers, allowing them to make and execute novel plans. Therefore, the honesty, caring, and compassion for workers, and equal and ethical treatment of ethical leaders inspires workers through a sense relating to dignity that helps to activate employee's understanding of overwork thus consequences to innovative thoughts. Hence, our team hypothesized:

H1: There is a positive relationship between ethical leadership with the creativeness of employees.

\section{Ethical Leadership and Knowledge Sharing}

People's behaviors, consistent with the SET (social exchange theory), were founded over the concept of reciprocities. According to Ma et al. (2013), the fundamental law of SET is reciprocity that theorizes people's control over the exchange of information by them via those important to one needs to be gleaned from mutual costs and benefits. Knowledge sharing in the workplace denotes the exchanging of facts related to the job, records, and habits of work, proficiencies, as well as individual's experience. The primary benefits of ethical heads remain, they foster reciprocal contact as well as trust that encourages workers to contribute to information exchange in the workplace (Le \& Lei, 2018). Sharing appropriate, one-of-akind, and valuable material allows recipients to use it to complete job tasks, which can increase the chance of innovation. Misbah Hayat et al. (2020), for example, discovered that information exchange, both inner as well as external, has a positive impact on innovation.

In the current study, our team hypothesized ethical leaderships to encourage workers for exchanging expertise that will foster innovation. Workers are further probable for participating within knowledge creation and distribution in organizations where ethical leaders create policies to facilitate knowledge exchange as well as foster a complacent atmosphere. The formation of such an atmosphere promotes employee engagement and collaboration, as well as the growth of support along with 
relationships based on trust together with the leader(s) as well as colleagues. As a result, workers invest in knowledge building to sustain contact and promote teamwork, increasing the degree to which they add new concepts to their workplace. Hence, sharing of knowledge is suggested for being a means that cherishes workers' creativeness. Hence, proposing the subsequent proposition:

\section{H2: Sharing of knowledge intercedes the association of ethical leadership with employees' creativeness.}

\section{Ethical Leadership and Employee Intrinsic Motivation}

Intrinsic motivations are the psychosomatic environment in which the person is interested in a certain task out of his selfdetermination, rather than because of external incentives or powers associated with the work. As said by Yidong et al. (2013), self-sufficiency, self-directing resources, evolving guidance, as well as leadership reinforcement to complete difficult and nuanced assignments promote inherent motivation in workers. Contrasting to it, deadlines, threats as well as goals imposed are all related to low intrinsic levels of motivation. Ethical leaders include positive criticism, unremitting input over performances, instruction as well as training, assistance within job accomplishment, knowledge exchange, subordinate empowerment, and opportunities for self-direction, all of which assist workers in achieving difficult tasks and increasing their feelings of autonomy, pride, and trust (Feng et al., 2018). Thus, as an ethical leader makes such things well-defined that every distinct worker shall be handled equally, reasonably, as well as ethically within jobs accomplishments of them, such workers experience a higher sense of self-sufficiency, stability, understanding, as well as integrity that increases intrinsic motivation. Shareef and Atan (2019) meant that intrinsic motivation of an individual's intensity remains crucial for deciding activities that will contribute to innovative job success since intrinsic motivation distinguishes what someone will and will do. Individuals who are intrinsically inspired have a stronger propensity to pursue curiosities, understand, and search out innovation.

Furthermore, the internally driven person remains further probable in converting one's inspiration towards a higher position along with appreciated work tasks, especially those marked by difficulty, ingenuity, and mission requirements that are demanding. As a result, there is a dispute that a leadership that is ethical in style encourages workers' innate enthusiasm that in succession stimulates one's innovation. Therefore:

H3: There is a linkage created by intrinsic motivations that intercede between ethical leaderships as well as workers' creativeness.

\section{Ethical Leadership and Psychological Empowerment}

Psychological or inner empowerments signifies the psychological status of an individual that includes significance (one's feelings about the importance of task done by an individual), integrity (person's capacity for fulfilling his work, expressly efficiency of oneself), determination of self (person's sense of independence along with control about one's job or task), as well as effect (person's perspective about a degree leading to such an extent that one's actions may influence job outcomes) throughout the workplace (Ahmad \& Gao, 2018). Ethical leaders recognize their employees' developmental needs and wellbeing to allow their growth and effectiveness in their work. Seeking out educational programs for workers and demonstrating encouragement by making ethical decisions, ethical heads help workers achieve a "work-role match" as well as higher standards of self-efficiency, promoting sense along with competency. Ethical leaders promote a sense of self strength of mind as well as impacts in their workers by offering accountability, upholding human rights, facilitating involvement in decision making, and maintaining equality (Sahraei Beiranvand et al., 2021). To summarize, ethical leaders promote employee psychological empowerment through equal care, respect, security, and the making of ethical evaluations.

Javed et al. (2017) argue over the main determining factors of innovation to be psychological empowerment. Individuals who have been granted authority are required to participate in innovative practices. Similarly, Qing et al. (2019) argue that individuality exists as a key characteristic within innovative people. In the opinion of Duan et al. (2018), as workers feel that one's tasks are essential as well as significant for them along with their company, they work further for finding creative methods for solving challenges, hence those worker's creativeness is welcomed. As a result, it is anticipated that employee social empowerment would play a role to explain one's imagination. Like it is previously mentioned, ethical leaders demonstrate dignity, supportiveness as well as equal care of their followers, thus increasing the latter's sovereignty and psychological empowerment (Ali Chughtai, 2016). Employees who comprise of a higher degree relating to psychological empowerments are more likely to participate in and work on finding innovative approaches to problem-solving, which encourages innovation. As a result, it is suggested for ethical leaderships to influence worker's ingenuity via psychosomatic empowerments. Hence:

H4: Psychological empowerments of an employee intercedes a correlation relating to ethical leaderships with employee's creativeness. 


\section{Employee's Creativity and Organizational Innovation}

Individuals, according to Jiang et al. (2012), remain the main foundation of creativity. Creative workers are brighter for finding utilities relating to newer creations, along with newer ways for utilizing pre-existing product procedures, and/or products. As a result, certain workers may be regarded as an organization's ultimate source of high creative results. Furthermore, these workers not only generate innovative ideas but also carry out the requisite preparations to put such ideas into action. Furthermore, existing as champions of an idea, innovative workers remain more probable for serving as a mentor as well as to put an impact on various other workers within work-place, hence, also changing them into being a good idea creator (Ouakouak \& Ouedraogo, 2017). A revolutionary concept of innovative workers may likewise be passed into further workers within that company for one's creation as well as use that can contribute to the promotion and development of creativity relating to an organization. Individual-level innovations are also supposed to contribute to creative results at the corporate level through the generation and application of novel plans. Hence being theorized that:

H5: Creativity of employee devices a constructive association with innovations that are related to the organization.

\section{Ethical Leadership and Organizational Innovations}

Organizational creativity, according to Shafique et al. (2020), is the development of essential and valuable innovative goods in organizational environments. Such viewpoint is further consistent with Duan et al. (2018) p.561 theory relating to product innovations: "new products and/or services introduced to fulfill an external user's or market need." Many reports over ethical leaderships have concentrated upon individuals as well as group's level of ethical (that is, ethical conduct, misconducts, etc.) as well as behavioral conclusions (that is, satisfactions, engagements, creativeness, etc.). Hardly any studies have attempted into exploring the influence relating to ethical leadership over firm results namely, economical, institutional, as well as ecofriendly efficiency. In comparison to various other leadership models, the information appears to have an absence of an analysis of the relationship between ethical leadership as well as corporate innovations, implying the desire to research further for exploring ethical leadership-firmed results via personal case studies.

Ethical heads are required to promote competition along with firms' proclivity to innovate. Ethical officials, as moral bosses, are often concerned with the effect of their employment on workers, the company, also society, as well as they entrench sense into chores. As a result, workers recognize the relevance of their work to the company and devote more time to developing new products/services to meet corporate goals (Chen \& Hou, 2016). Employees feel physically more comfortable when discussing new ideas with conscientious leaders because they are considered to possess qualities such as altruism, fairness, morality, dignity, and dedication. Employees, on the other hand, restrain themselves from expressing morals, beliefs, and new thoughts because they perceive their representatives to be unethical people who go against ethical standards and values (such as engaging in self-serving behavior).

Furthermore, ethical heads differentiate one-selves via promoting dual-ways dialogue within communities, as these leaders often pay attention to one's supporters sincerely, also wholeheartedly. They often encourage workers to express their interests and opinions, which inspires workers for coming up having novel ideas to develop job practices, strategies, as well as processes specific for one working unit and the whole company. This leader exhibits behavior afar from traditional leaderships, hence remains impactful to encourage their supporters to guarantee market achievement relating to the innovations of the organization (Kantabutra \& Saratun, 2013). Within the research and development (R\&D) environment, the success of followers is measured on metrics that are grounded based on quality rather than quantity-based metrics; hence, extremely technical instead of conventional leadership approach remains crucial to maximizing outputs based on quality (Riivari et al., 2019). Furthermore, in addition to internal positions, ethical leaders can take on external roles such as championing and boundary spanning to decide consumer demands and the efficient marketing of technologies. Hence, this being argued that ethical leadership's optimistically correlated to creativity; specifically, with a firm proclivity for innovating, along with the successfulness relating to innovations. Henceforth:

H6: Organizational innovations are promoted by ethical leadership.

H7: Ethical leadership nurtures organizational innovations via creativeness.

\section{METHODOLOGY}

\section{Study Sample Selection}

This research used a field analysis that was based on surveys with specimens of 245 workers as well as correlated executives originating at the ICT companies to assess hypothesized relationships. The ICT firms that were included met dual conditions relating to inclusion like specimen firms within the current study: a least of four years as well as consistent growth of software. Out of 143 of them, the representatives of 97 companies expressed their willingness to participate in this study. The participants were R\&D personnel's owners/managers/direct bosses. The leader of each group presented a list of R\&D 
personnel engaged in problem analysis, architecture, and software creation. Five of the participants did not apply their comments.

In terms of company scale and type of job done, the firms in the study are almost equal. According to Ledimo (2015), every company is undersized, containing 3 to 17 workers, hence every employee participates in the procedure relating to designing novel and/or upgraded goods. There are two explanations why such a sample was selected. Due to the essence of the company practices performed by these companies, it is necessary to discuss ingenuity (individual level) and organizational advancement first. Even though the software development positions offered by these companies are synonymous with the need for imagination, academics bestowed less consideration relating to fields of creativeness as well as innovations within the current field. Likewise, the part of the software developments remains intensifying within innovations relating to industry; hence, the specimen being adequate for calculating organizational innovations. Secondly, small-scale entrepreneur companies, as is opposed to big companies, are likely to exhibit greater creative activities due to one's "greater versatility", possibly having "younger and more growth-oriented employees" (Makaroff et al., 2014) p. 29. As a result, this looks fair to deem the current study to be the best fit for achieving our study goal. The research group included 201 men $(82.3 \%)$ as well as 31 women $(12.7 \%)$. The usual oldness of the workforce was 38 years. 72.4 percent of the overall specimen was alumni, with $37.8 \%$ holding an undergraduate degree. Employees had an overall term of 2.5 years. The average life span, as well as proportion of the companies, is 4.8 years along with 7.4 workers, correspondingly.

\section{Data Collection Procedures}

The data was gathered in dual stages, beginning with personalized interviews with the managers or owners having ten businesses. The main aim of personalized interviews was for defining the firm's activities relating to software development. Furthermore, the questionnaire was given to the managers and chosen workers of these companies to see if the questionnaire elements were easy to interpret and appropriate. The ease and importance of the questionnaire elements are overwhelmingly accepted by the participants. After weeks (two weeks), the dual-phase structured collection of data process starts. During the primary process, every worker fully completed the questionnaire given to them, although heads of the department were only proved with a section of the questionnaire given to them. After a month's pause, all leaders completed the unresolved portions comprising the questionnaires in the second process. During operating hours, all questionnaires were filled. The investigators remained on hand for answering any questions as well as collect completed questionnaires of the surveys during this exercise. Having all the answerers from Vietnam, every item was deciphered to the Vietnamese language, then translated back to the English language for ensuring similarities in the concepts. Every item was deliberated over a Likert scale of five points, excluding performances relating to innovation (Chen \& Boore, 2010).

The questionnaire's employee section included constructs such as ethical leadership, experience imparting, empowerments that are psychological, as well as inherent motivations. Both workers were asked for including demographic details (that is, genders as well as ages) as well as work-concerning data (for example, tenure of job). Leaders' answer was gathered over four weeks on two independent surveys. Within the very first survey, executives were required for providing details about their organization's inventions as well as the age of the company. Within the survey that was held second, all were asked to give ratings to the creativeness of one's juniors. The chief reason to perform the leaders' polls on two separate phases was for minimizing the possibility relating to exaggerated as well as bias results, which may have occurred if leads have to fill up the sections on organizational-level innovations and employee imagination at the identical time.

\section{Individual-Level Constructs}

Ethical leadership. Arredondo Rucinski and Bauch (2006) ten items measurements were utilized for assessing ethical leadership within the current report. Contestants were required to score one's direct supervisors (that is, leaders, managers, in-charges, supervisors, etc.). "My boss listens to what workers have to say," for example. The values relating to Cronbach's $\alpha$ happened to be 0.91 .

Knowledge sharing. We used Liu and Tsai (2008) eight items scale to assess information exchange. Participants indicated how much they had aligned themselves with habits in the previous year. "I consciously use IT tools available in the organization to share my knowledge," for example. The values relating to Cronbach's $\alpha$ happened to be 0.78 .

Intrinsic motivations. Kunz and Pfaff (2002) developed a five-item scale to evaluate inherent motivation. Employees expressed how often each comment is applied to them in the context of their current work. "I enjoy coming up with innovative ideas or goods/services" and "I enjoy improving existing goods/services or procedures" are two examples. The values relating to Cronbach's $\alpha$ ( 0.77 ) guaranteed reliability.

Psychological empowerments. A scale of 12-item devised by Miguel et al. (2015) was modified for assessing the relational empowerment construct. The example elements are "I have a significant influence on what happens in my organization" and "I have substantial flexibility in determining how I do my work." 0.82 was the value of Cronbach's $\alpha$. 
Creativity. The ingenuity of the supporters happened to be a variable that was dependent on this analysis. An emphasis of the current thesis remains on R\&D personnel's innovation and also their proclivity for transforming new ideas towards revolutionary services/ goods. Consequently, together, the idea's development, as well as its implementation through such employees, must be considered when measuring innovation. This research adopted a 13-item scale developed by Kaufman et al. (2009). Leads to the team measured their employees' innovation four weeks subsequently after the employees rated leaderships. My employee, for example, "promotes and champions ideas to others" and "serves as a good example for creativity." The dependability of the scale happened to be 0.95 .

Control. Since work duration, as well as level of education of the supporters, are linked to innovation, these variables were used as control variables. According to Kaufman et al. (2009), imagination is the product of acquired skills, practice, and formal schooling. According to Kormanik and Rocco (2009), experience represents information that can influence creative behavior. As a result, our team utilized career terms as a measure of expertise.

\section{Firm-Level Constructs}

Ethical leadership as well as firm-level creativity. This study builds on previous findings by focusing on ethical leadership at the company level to forecast firm-level outcomes. As a result, employee ratings in ethical leadership were gathered towards the level of a firm. Moreover, for evaluating theories relevant regarding company-level innovations, ratings of the employees regarding their heads' ingenuity were collected to the level of the firm via taking averages of the statistics regarding each firm. The one-way ANOVA provided preliminary support to aggregate poor scores in ethical leadership. The outcomes told that the group's variations were considerably far from within the group's variations $(\mathrm{F}=2.08, \mathrm{p}<0.001)$. Intra-class correlations that are, $\mathrm{ICC}_{1}$ as well as $\mathrm{ICC}_{2}$ came out to be 0.47 as well as 0.91 , respectively. Moreover, 0.86 was the median Rwg (j) value was 0.88 , hence proving the aggregation to be appropriate regarding such variable. Our team also aggregated individual's creativeness marks relating to the level of firms (for each firm).

Organizational innovations. Since corporate creativity remains complex and difficult, there is no general understanding of how to calculate it. We describe creativity as a proclivity of a firm for producing an enhanced or else innovative product or service, also its performance for getting such goods or services to market. Such thing covers novel product, product modifications, and custom-based designs. Marketplace measurements of innovation, according to Riivari et al. (2019), are more rigorous and have a more accurate innovation index than standard measures of innovation. In the current analysis, the product of two ratios was used to measure organizational creativity: the innovativeness propensity coefficients as well as the product innovation's success. The creativeness propensity coefficients, which is measured as a ratio of revenue produced by the innovation of the products for overall sellings, reflect a firm's orientation toward innovation. Product innovation success is defined as the ratio of revenue produced by the innovation of the products to expenses or amounts expended over such revolutions. Such methodology remains reliable to the work of Hagger et al. (2019). Furthermore, Shanker et al. (2017) contend that it's a superior measure regarding innovations than metrics calculated using R\&D expenses.

Controls. Age of the organization remained a control variable within the current analysis, as preceding studies of the research refer to its constructive relationship with the innovation of the firm (Shanker et al., 2017).

\section{DATA ANALYSES AND RESULTS}

\section{Individual-Level Analysis}

Descriptive statistics. Values of mean, standard deviation as well as $\alpha$ coefficient, along with correlation between every individual's levels of variables, had been shown in Table 1. The inter-correlation validated the creativity to be significantly and positively related with psychological empowerments $(r=0.22, p<0.01)$, knowledge sharing $(r=0.13, p<0.05)$, intrinsic motivations $(r=0.23, p<0.01)$ as well as ethical leaderships $(r=0.32, p<0.01)$. Ethical leaderships have noteworthy positive relatedness with psychological empowerments $(r=0.22, p<0.01)$, knowledge sharing $(r=0.13, p<0.01)$ as well as intrinsic motivations $(r=0.25, p<0.01)$.

Table 1: Inter-Correlations and Descriptive Statistics

\begin{tabular}{|c|c|c|c|c|c|c|c|c|c|}
\hline Variable & Mean & S.D. & 1 & 2 & 3 & 4 & 5 & 6 & 7 \\
\hline 1. Education & - & - & - & & & & & & \\
\hline 2. Experience & 3.97 & 4.27 & -0.08 & - & & & & & \\
\hline 3. Ethical Leadership & 3.93 & 0.77 & -0.10 & -0.16 & $(0.88)$ & & & & \\
\hline 4. Psychological Empowerment & 4.06 & 0.69 & 0.21 & $0.22 * *$ & $0.41 * *$ & $(0.78)$ & & & \\
\hline 5. Knowledge Sharing & 4.11 & 0.71 & $0.19 *$ & $0.13 * *$ & $0.61 * *$ & $0.33 * *$ & $(0.91)$ & & \\
\hline 6. Intrinsic Motivation & 3.99 & 0.82 & -0.07 & 0.09 & $0.25 * *$ & $0.23 * *$ & 0.21 & $(0.83)$ & \\
\hline 7. Individual Creativity & 4.12 & 0.75 & 0.24 & 0.07 & $0.32 * *$ & $0.34 * *$ & $0.18 *$ & $0.34 * *$ & $(0.89)$ \\
\hline
\end{tabular}


Notes: $N=245 . \quad * p<0.05$ and $* * p<0.01, \quad 1=$ Education, $2=$ Experience, $3=$ Ethical Leadership, $4=$ Psychological Empowerment, 5=Knowledge Sharing, 6=Intrinsic Motivation, 7=Individual Creativity.

Individual-level hypothesis test. Table 2 represents the outcomes related to the analysis hypotheses over direct as well as indirect associations with variables of the outcome. Such theories were evaluated using Mplus 7 because the evidence from the current study was verified in organizations, as well as the models included cross-level correlations amid ethical leaderships (on company's levels), intermediaries (on the employee levels), as well as worker's imagination (on the level of an individual).

Table 2: Multilevel Modelling Results for Creativity

\begin{tabular}{|c|c|c|c|c|}
\hline Variable & 1 & 2 & 3 & 4 \\
\hline Education & 0.12 & & & \\
\hline Experience & 0.08 & & & \\
\hline Ethical Leadership & $0.33 * *$ & & & \\
\hline Education & & $0.19 * *$ & & \\
\hline Experience & & $0.06^{*}$ & & \\
\hline Ethical Leadership & & $0.41 * *$ & & \\
\hline Education & 0.12 & & & \\
\hline Experience & 0.02 & & & \\
\hline Ethical Leadership & 0.19 & & & \\
\hline Psychological Empowerment & $0.33 * *$ & & & \\
\hline Education & & & $0.14 * *$ & \\
\hline Experience & & & $0.10^{* *}$ & \\
\hline Ethical Leadership & & & $0.39 * *$ & \\
\hline Education & 0.11 & & & \\
\hline Experience & 0.02 & & & \\
\hline Ethical Leadership & 0.17 & & & \\
\hline Knowledge Sharing & $0.35 * *$ & & & \\
\hline Education & & & & 0.03 \\
\hline Experience & & & & 0.04 \\
\hline Ethical Leadership & & & & $0.28 * *$ \\
\hline Education & 0.08 & & & \\
\hline Experience & 0.03 & & & \\
\hline Ethical Leadership & $0.40 * *$ & & & \\
\hline Intrinsic Motivation & 0.17 & & & \\
\hline
\end{tabular}

Notes: $N=245 . * p<0.05$ and $* * p<0.01,1=$ Individual Creativity, $2=$ Psychological Empowerment, 3=Knowledge Sharing, $4=$ Intrinsic Motivation.

To analyze the straight and facilitated impacts, this report used the multi-level meditational modeling approach, as Krull and MacKinnon in 2001 did. The current approach merges the meditational analysis method developed by Baron and Kenny (1986) into hierarchical linear models. Furthermore, this approach involves the analysis of both direct and mediated effects. Furthermore, for the multilevel mediational modeling methodology, the Sobel test is used to assess the magnitude of the mediating effect. Employee work tenure and educational degree are called control variables within every model of hierarchy.

Outcomes represented within Table 2 provide empirical support for $\mathrm{H} 1$ that denotes, that the ethical leadership anticipates employee's creativeness $(\beta=0.33, p<0.01)$. Likewise, the results endorse $\mathrm{H} 2$ as well as $\mathrm{H} 4$, which states the information exchange as well as psychological empowerments to act as a moderating force regarding the "ethical leadership-employee creativity" connections. Outcomes show the ethical leaderships to be constructively connected to knowledge sharing $(\beta=$ $0.39, p<0.01)$, as well as knowledge sharing to be constructively linked to creativeness $(\beta=0.35, p<0.01)$. Furthermore, when sharing of knowledge was familiarized accompanied by ethical leaderships, the linkages amid ethical leaderships with creativities turned out to be irrelevant $(\beta=0.17, \mathrm{~ns})$, demonstrating the existence of full intervention. Likewise, ethical leadership also remains to be connected to psychological empowerments $(\beta=0.41, p<0.01)$, as well as psychological empowerments, which remain linked to creativities $(\beta=0.33, p<0.01)$. Hence, when psychological empowerments were initiated together with ethical leaderships, the association amid ethical leaderships as well as creativeness turned out to be irrelevant $(\beta=0.19, \mathrm{~ns})$, backing up the existence of full intervention. For $\mathrm{H} 3$, verdicts were unsuccessful in supporting the interceding function of intrinsic motivations as, notwithstanding the noteworthy impact of ethical leaderships over intrinsic motivations $(\beta=0.28, p<0.01)$, the association amid intrinsic motivations with creativeness remained irrelevant $(\beta=0.17$, ns). 


\section{Organizational-Level Analysis}

Descriptive analyses. Table 3 shows the outcomes of descriptive studies for organizational-level factors, including means, standard deviations, and associations. The findings revealed no important relationship between company age and the concerning variable. Ethical leaderships discovered to device noteworthy progressive association with organizational level's creativeness $(r=0.41, p<0.01)$ as well as organizational innovations $(r=0.37, p<0.01)$. Moreover, creativeness was considerably linked to innovations $(r=0.30, p<0.05)$. The evocative study stipulates tentative pieces of evidence regarding the possible effect of ethical leaderships over corporate innovations, encouraging us for pursuing more studies for exploring the pivotal association between such variables.

Table 3: Mean, Standard Deviation and Correlation Coefficients for Organizational-Level Variables

\begin{tabular}{|c|c|c|c|c|c|}
\hline Variable & Mean & Std. Dev. & 1 & 2 & 3 \\
\hline 1. Firm Age & 3.99 & 4.05 & & & \\
\hline Ethical Leadership & 4.11 & 0.67 & -0.16 & & \\
\hline 3. Creativity & 4.17 & 0.73 & 0.09 & $0.41 * *$ & \\
\hline 4. Organizational Innovation & 2.32 & 0.61 & 0.22 & $0.37 * *$ & $0.30 *$ \\
\hline
\end{tabular}

Notes: $N=245 . * p<0.05$ and $* * p<0.01,1=$ Firm Age, $2=$ Ethical Leadership, $3=$ Creativity.

Organizational-level hypothesis testing. Our team used hierarchical regression analysis for assessing how much ethical leadership impacts corporate imagination and innovation. H6 asserts ethical leaderships to have a strong beneficial effect on corporate creativities. Outcomes of the regression analysis tell that, next to regulating the impact of a firm's ages, ethical leadership progressively encourages organizational innovations $(b=0.37, p<0.01)$ (Table 4). Besides that, ethical leadership progressively influences a firm's level of creativeness $(b=0.41, p<0.01)$ when the impact of the firm's age is coordinated. $\mathrm{H} 7$ denotes creativity to intercede the impact of ethical leadership over organizational innovations. The creativeness remains considerably $(p<0.10)$ liked to organizational innovations $(\mathrm{b}=0.16, p=0.081)$, this information moderately supports $\mathrm{H} 7$. Obeying the technique of Baron and Kenny in 1986, our team evaluated the incidental impacts as well as levels of importance. Though, the outcomes did not assist the existence of mediations $(b=0.037$, ns), therefore discarding H7.

Table 4: Results of Hierarchical Regression Analysis

\begin{tabular}{|c|c|c|c|}
\hline \multirow[t]{2}{*}{ Variable } & \multicolumn{2}{|c|}{ Organizational Innovation } & Creativity \\
\hline & Model 1 & Model 2 & Model 1 \\
\hline Firm Age & 0.13 & 0.09 & 0.07 \\
\hline Ethical Leadership & $0.37 * *$ & $0.31 * *$ & $0.41 * *$ \\
\hline Creativity & & $0.16^{* *}$ & - \\
\hline$R^{2}$ & $0.42 * *$ & $0.48 * *$ & $0.29 * *$ \\
\hline$\Delta R^{2}$ & $0.42 * *$ & $0.10 *$ & $0.29 * *$ \\
\hline
\end{tabular}

Notes: $N=245 . *_{p}<0.05$ and $* * p<0.01$

\section{DISCUSSION}

The current analysis adds information over leadership as well as creativity in both analytical and analytical ways. For the first time, the impact relating to ethical leadership over organizational innovations, plus the mediating role of imagination, was explored in this report. The research also investigated the impact relating to ethical leadership over workers' innovation via intrinsic motivations, psychosomatic encouragement, as well as sharing of knowledge. Two studies were carried out: first on individual's level of conclusions as well as another one on firm's level of resulting variables. According to results, ethical leadership devices an important progressive influence over worker innovation, internal engagement, psychological empowerments, as well as information impartment. Furthermore, ethical leadership was discovered to have strong ties with corporate creativity, meaning ethical leaderships to be a primary element to promote individual and organization's level of success.

The results are essential for the underneath motives: Firstly, recent research over ethical leadership yields inconclusive findings, indicating that further research is required to validate its effect on organizational attitudes and outcomes. The current research was conducted in a "real-world environment," and it shows that ethical leadership remains a good predictor relating to employee innovation. Secondly, as opposed to individualistic western societies, ethical leadership is required to maximize organizational results in a group society. Given Vietnam's collectivist culture, ethical leadership's supposed to remain extra successful within Vietnamese organizations rather than within a Western organization. 
The interceding function of psychosomatic empowerments relating to employee's creativeness is important, suggesting employee's psychological empowerment to have a convincing impact on creativeness. Such partnership exists because relational empowerment provides a sense relating to autonomy for thinking productively as well as resourcefully. The association amid knowledge sharing as well as worker imagination remains substantial; this demonstrates that workers to be inspired by knowledge-sharing cultures as well as believe one's job to be a respect for serving humankind. The results regarding the negligible impact of intrinsic motivations suggest that motivations to be an essential component, also criterion regarding innovation, and hence has negligible meaningful impact individually.

Organizational creativity and ethical leaderships have constructive as well as an important partnership. These results suggest that ethical leaderships have a progressive impact not only over workers but also over corporate innovations as ethical heads demonstrate one's interests as well as considerations regarding organizational innovations. They embrace new solutions and work on them to give their companies a strategic edge over their rivals, as well as to improve employee morale and empowerment. The suggested theory amid creativeness with organizational innovations presented an insignificant interrelation $(\beta=0.16, p=0.081)$. For a variety of factors, this partnership could be meaningless. Likely, proposals presented by workers of some organizations are not taken seriously or as seriously as they are in others. Consequently, such actions by their organizations can restrict their ability to innovate. Another explanation may be a lack of understanding, in which new concepts are not articulated properly, causing uncertainty in minds of the leaders, or his struggle for correctly interpreting the plans that remain important relating to creativity. The findings suggest that ethical leaderships have an absolute effect on an employee's creativities, hence this absolute impact disappears as intermediaries are added. The meaning of this is that the ethical leaderships do not actively encourage innovation; more exactly, it develops and fosters creativity through a variety of mechanisms. This relationship may be attributed to Vietnamese society's collectivist ethos (Hofstede, 1980), and the application of imagination must face many obstacles, so creativity is still in the shadows.

The research has significant scientific and managerial ramifications. First, in comparison to the previous analysis, the current analysis introduces as well as tests the hypothesis that ethical leaderships are a significant indicator of creativities that sequentially encourages organizational innovations. The researchers raise the question of "how" ethical leadership affects innovation, elucidating the fundamental processes by which ethical leaders foster creativity. Secondly, the proposed intermediary function relating to the imagination for ethical leadership's organizational innovation relations attempts to elucidate a possible framework for fostering organizational innovation. About the fact that the connection amid creativities as well as novelties is negligible, the discoveries allow researchers to conclude that an evident degree of creativeness to be required for encouraging innovations. If managements struggle for raising innovation to such a degree, the investments within the human resource as well as attempts for improving human's capitals may be for naught as well as could be converted to a cost. Moreover, since respondent companies have an average age of 4.18 , the negligible relationship between imagination and innovation may be due to methodological issues. Therefore, the pace of innovation, as well as the nature of innovation, can be essential factors. Third, the research adds to the methodological approach by using a more empirical, market concerning metric regarding corporate innovations instead of idiosyncratic measures, like it was traditionally seen in various headship types. The latest research investigating another headship style of innovations nexuses confirm the toughness of a market concerning measures with regards to the objectivities as well as favor it to measures based on perception. This metric can also be used as a surrogate for entrepreneurial company creativity within the countries that are developed as well as throughout industries, and also within the emerging markets where further metrics, namely copyrights stand missing. Such a method differs from others in that this encapsulates proclivity for creativity as well as the outcome of the innovations, making it a predictor of firm competitive advantage. Fourth, the study's results have consequences for administrators. To engage for innovation, heads must obey values of psychological empowerments as well as information exchange guidelines, consistent with the mediating frameworks for creativity. Managers can boost ingenuity in terms of the volume and novelty of innovations to the point that these ideas are accepted by the organization, raising the likelihood of corporate innovations. Lastly, cultivating as well as honing ethical leadership skills can assist the administration in building an environment conducive to the proclivity for creativity.

\section{LIMITATIONS AND FUTURE DIRECTIONS}

Aside from making a significant contribution, the study has drawbacks that must be acknowledged when elucidating the study's results. Employee creativity ratings given solely via leader can conclude in exaggerated grading regarding favored workers. A cross-sectional research design often restricts knowledge regarding how ethical leadership influences imagination as well as innovations across tenure. While current analysis suggests information technology to be an emerging area of exploration regarding psychology as well as management researches, further research is required for concentrating on the initiators as well as requirements of ethical leadership, and also the effect on outcomes of the workplace.

Forthcoming studies in other fields and through venture companies can be undertaken to assess whether ethical leaderships to be similarly essential to promote entrepreneurship as well as to enhance competitiveness regarding emerging start-ups in another perspective. Researchers would benefit from a cross-regional as well as cross-cultural analysis to better understand 
how ethical leadership impacts workers as well as the firm's results. Furthermore, more information to be needed on the ethical behaviors of executives in service sectors, such as hospitals, where nurses and doctors control workers' actions to become more artistic or imaginative. This study further demonstrates that executives must be encouraged to consider employee innovations to incorporate creativity within an organization. Likewise, since ethical leaderships have an absolute influence over workers' innovation, would it have a different effect than other similar leadership models, such as transformational, inspiring, and honest leadership? Furthermore, future studies may look at how, in the absence of group as well as the unity of worker's ingenuity, ethical leaderships take organization's progress towards manufacture. To deliver more accurate results, upcoming discoveries must be capable of relying on extra factors namely employee and leader attitude, internal locus of influence, and organizational confidence.

\section{CONCLUSION}

Ethical policies encourage workforce information exchange and social encouragement, which encourages them over thinking innovatively. Ethical heads are those who have the authority to put these innovative innovations into action to improve corporate creativity. Top management will create a strategic edge through innovative staff and organizational creativity. The design of an ethical climate empowers workers and encourages them to explore the production of new ideas, which improves firm-level creativity. Favoritism is common in less developed nations and can be a barrier when it comes to handling workers. Employees do not earn equal wages and rewards because of sycophant as well as favoritism in an organization. Workers have fewer chances for demonstrating their ingenuity as their bosses do not encourage it. Although, current research proposes ethical leadership as a solution for those challenges that stifle innovation and argues for the possible advantages that ethical leadership might bring. Firms should encourage ethical leadership preparation and training to improve innovative thought and corporate creativity. This report, on the other hand, proposes ethical leadership as a solution to the challenges that stifle creativity and argues for the potential benefits that ethical leadership can offer. Firms should promote ethical leadership planning and instruction to develop creative thinking as well as organizational innovations.

\section{STATEMENT OF COMPETING INTEREST}

This statement is to certify that the authors of this research hereby declare no competing interests regarding this article's publication.

\section{AUTHOR CONTRIBUTION}

Anantha Raj A. Arokiasamy worked on the draft, carried the statistical analysis, data collection, and Massoud Moslehpour performed interpretations, validation, and technical parts. Every author has a significant contribution to this article.

\section{ACKNOWLEDGEMENT}

We would like to thank all the independent reviewers of HSSR who helped us to make this paper significantly better.

\section{REFERENCES}

1. Acar, O. A., Tarakci, M., \& van Knippenberg, D. (2019). Creativity and Innovation Under Constraints: A CrossDisciplinary Integrative Review. Journal of management, 45(1), 96-121. https://doi.org/10.1177 /0149206318805832

2. Ahmad, I., \& Gao, Y. (2018). Ethical leadership and work engagement: The roles of psychological empowerment and power distance orientation. Management decision, 56(9), 1991-2005. https://doi.org/10.1108/MD-02-2017$\underline{0107}$

3. Ali Chughtai, A. (2016). Can ethical leaders enhance their followers' creativity? Leadership (London, England), 12(2), 230-249. https://doi.org/10.1177/1742715014558077

4. Arredondo Rucinski, D., \& Bauch, P. A. (2006). Reflective, ethical, and moral constructs in educational leadership preparation: effects on graduates' practices. Journal of educational administration, 44(5), 487-508. https://doi.org/10.1108/09578230610683778

5. Asif, M., Miao, Q., Jameel, A., Manzoor, F., \& Hussain, A. (2020). How ethical leadership influence employee creativity: A parallel multiple mediation model. Current psychology (New Brunswick, N.J.). https://doi.org/10.1007/s12144-020-00819-9

6. Caniëls, M. C. J., \& Rietzschel, E. F. (2013). A Special Issue of Creativity and Innovation Management: Organizing Creativity: Creativity and Innovation under Constraints: Call for Papers. Creativity and innovation management, 22(1), 100-102. https://doi.org/10.1111/caim.12010

7. Caniëls, M. C. J., \& Rietzschel, E. F. (2015). Organizing Creativity: Creativity and Innovation under Constraints. Creativity and innovation management, 24(2), 184-196. https://doi.org/10.1111/caim.12123 
8. Chen, A. S.-Y., \& Hou, Y.-H. (2016). The effects of ethical leadership, voice behavior and climates for innovation on creativity: A moderated mediation examination. The Leadership Quarterly, 27(1), 1-13. https://doi.org/10.1016/j.leaqua.2015.10.007

9. Chen, H.-Y., \& Boore, J. R. P. (2010). Translation and back-translation in qualitative nursing research: methodological review. Journal of clinical nursing, 19(1-2), 234-239. https://doi.org/10.1111/j.13652702.2009.02896.x

10. Duan, S., Liu, Z., \& Che, H. (2018). Mediating influences of ethical leadership on employee creativity. Social behavior and personality, 46(2), 323-337. https://doi.org/10.2224/sbp.6160

11. Feng, J., Zhang, Y., Liu, X., Zhang, L., \& Han, X. (2018). Just the Right Amount of Ethics Inspires Creativity: A Cross-Level Investigation of Ethical Leadership, Intrinsic Motivation, and Employee Creativity. Journal of business ethics, 153(3), 645-658. https://doi.org/10.1007/s10551-016-3297-1

12. Ghosh, K. (2015). Developing organizational creativity and innovation: Toward a model of selfleadership,employee creativity,creativity climate and workplace innovative orientation. Management research review, 38(11), 1126-1148. https://doi.org/10.1108/MRR-01-2014-0017

13. Hagger, M. S., Hankonen, N., Kangro, E. M., Lintunen, T., Pagaduan, J., Polet, J., Ries, F., \& Hamilton, K. (2019). Trait Self-Control, Social Cognition Constructs, and Intentions: Correlational Evidence for Mediation and Moderation Effects in Diverse Health Behaviours. Applied psychology : health and well-being, 11(3), 407-437. https://doi.org/10.1111/aphw.12153

14. Hon, A. H. Y., \& Lui, S. S. (2016). Employee creativity and innovation in organizations: Review, integration, and future directions for hospitality research. International Journal of Contemporary Hospitality Management, 28(5), 862-885. https://doi.org/10.1108/IJCHM-09-2014-0454

15. Javed, B., Khan, A. A., Bashir, S., \& Arjoon, S. (2017). Impact of ethical leadership on creativity: the role of psychological empowerment. Current Issues in Tourism, 20(8), 839-851. https://doi.org/10.1080/1 3683500.2016 .1188894

16. Jiang, J., Wang, S., \& Zhao, S. (2012). Does HRM facilitate employee creativity and organizational innovation? A study of Chinese firms. International Journal of Human Resource Management, 23(19), 4025-4047. https://doi.org/10.1080/09585192.2012.690567

17. Kantabutra, S., \& Saratun, M. (2013). Sustainable leadership: honeybee practices at Thailand's oldest university. International journal of educational management, 27(4), 356-376. https://doi.org/10.1108/09513541311316304

18. Kaufman, J. C., Cole, J. C., \& Baer, J. (2009). The Construct of Creativity: Structural Model for Self-Reported Creativity Ratings. The Journal of Creative Behavior, 43(2), 119-134. https://doi.org/10.1002/j.21626057.2009.tb01310.x

19. Kormanik, M. B., \& Rocco, T. S. (2009). Internal versus external control of reinforcement: A review of the locus of control construct. Human Resource Development Review, 8(4), 463-483. https://doi.org/10.1177/15344 $\underline{84309342080}$

20. Kunz, A. H., \& Pfaff, D. (2002). Agency theory, performance evaluation, and the hypothetical construct of intrinsic motivation. Accounting, organizations and society, 27(3), 275-295. https://doi.org/10.1016/S0361-3682(01)00031-9

21. Le, P. B., \& Lei, H. (2018). Fostering knowledge sharing behaviours through ethical leadership practice: the mediating roles of disclosure-based trust and reliance-based trust in leadership. Knowledge Management Research \& Practice, 16(2), 183-195. https://doi.org/10.1080/14778238.2018.1445426

22. Ledimo, O. (2015). An Exploratory Study Of Factors Influencing Organisational Justice Among Government Employees. Journal of applied business research, 31(4), 1549. https://doi.org/10.19030/jabr.v31i4.9336

23. Liu, P.-L., \& Tsai, C.-H. (2008). Using Analytic Network Process to Construct Evaluation Indicators of Knowledge Sharing Effectiveness in Taiwan's High-tech Industries. Asian journal on quality, 9(2), 99-117. https://doi.org/10.1108/15982688200800020

24. Locke, R., Castrucci, B. C., Gambatese, M., Sellers, K., \& Fraser, M. (2019). Unleashing the Creativity and Innovation of Our Greatest Resource-The Governmental Public Health Workforce. Journal of public health management and practice, 25 Suppl 2, Public Health Workforce Interests and Needs Survey 2017(2), S96-S102. https://doi.org/10.1097/PHH.0000000000000973

25. Ma, Y., Cheng, W., Ribbens, B. A., \& Zhou, J. (2013). Linking Ethical Leadership to Employee Creativity: Knowledge Sharing and Self-Efficacy as Mediators. Social behavior and personality, 41(9), 1409-1419. https://doi.org/10.2224/sbp.2013.41.9.1409

26. Makaroff, K. S., Storch, J., Pauly, B., \& Newton, L. (2014). Searching for ethical leadership in nursing. Nursing ethics, 21(6), 642-658. https://doi.org/10.1177/0969733013513213

27. Miguel, M. C., Ornelas, J. H., \& Maroco, J. P. (2015). Defining psychological empowerment construct: analysis of three empowerment scales. Journal of community psychology, 43(7), 900-919. https://doi.org/10.1002/jcop.21721 
28. Millet, C., Oget, D., \& Cavallucci, D. (2017). Open the 'black box' creativity and innovation: a study of activities in $\mathrm{R} \& \mathrm{D}$ departments. Some prospects for engineering education. European journal of engineering education, 42(6), 1000-1024. https://doi.org/10.1080/03043797.2016.1249341

29. Misbah Hayat, B., Umair, A., Muhammad Hasnat, B., Hassan, R., \& Xin, S. (2020). Unraveling the Effects of Ethical Leadership on Knowledge Sharing: The Mediating Roles of Subjective Well-Being and Social Media in the Hotel Industry. Sustainability (Basel, Switzerland), 12(8333), 8333. https://doi.org/10.3390/su12208333

30. Oliver, A. L., April, S., \& Kalish, Y. (2019). Organizational creativity-innovation process and breakthrough under time constraints: Mid-point transformation. Creativity and innovation management, 28(3), 318-328. https://doi.org/10.1111/caim.12326

31. Ouakouak, M. L., \& Ouedraogo, N. (2017). Antecedents of employee creativity and organisational innovation: an empirical study. International Journal of Innovation Management, 21(7), 1750060. https://doi.org/10.1142/S136391 $\underline{9617500608}$

32. Qing, M., Asif, M., Hussain, A., \& Jameel, A. (2019). Exploring the impact of ethical leadership on job satisfaction and organizational commitment in public sector organizations: the mediating role of psychological empowerment. Review of Managerial Science, 14(6), 1-28. https://doi.org/10.1007/s11846-019-00340-9

33. Riivari, E., Riivari, E., Lämsä, A.-M., \& Lämsä, A.-M. (2019). Organizational Ethical Virtues of Innovativeness. Journal of business ethics, 155(1), 223-240. https://doi.org/10.1007/s10551-017-3486-6

34. Sahraei Beiranvand, M., Beiranvand, S., Beiranvand, S., \& Mohammadipour, F. (2021). Explaining the effect of authentic and ethical leadership on psychological empowerment of nurses. Journal of nursing management. https://doi.org/10.1111/jonm.13246

35. Shafique, I., Ahmad, B., \& Kalyar, M. N. (2020). How ethical leadership influences creativity and organizational innovation: Examining the underlying mechanisms. European journal of innovation management, 23(1), 114-133. https://doi.org/10.1108/EJIM-12-2018-0269

36. Shanker, R., Bhanugopan, R., van der Heijden, B. I. J. M., \& Farrell, M. (2017). Organizational climate for innovation and organizational performance: The mediating effect of innovative work behavior. Journal of vocational behavior, 100, 67-77. https://doi.org/10.1016/j.jvb.2017.02.004

37. Shareef, R. A., \& Atan, T. (2019). The influence of ethical leadership on academic employees' organizational citizenship behavior and turnover intention: Mediating role of intrinsic motivation. Management decision, 57(3), 583-605. https://doi.org/10.1108/MD-08-2017-0721

38. Valaei, N., Rezaei, S., \& Emami, M. (2017). Explorative learning strategy and its impact on creativity and innovation: An empirical investigation among ICT-SMEs. Business process management journal, 23(5), 957-983. https://doi.org/10.1108/BPMJ-12-2015-0179

39. Yidong, T., Yidong, T., Xinxin, L., \& Xinxin, L. (2013). How Ethical Leadership Influence Employees' Innovative Work Behavior: A Perspective of Intrinsic Motivation. Journal of business ethics, 116(2), 441-457. https://doi.org/10.1007/s10551-012-1455-7

40. Yuen, H.-W., \& Balakrishnan, A. (2019). Next stop - teaching creativity and innovation in medical education. Medical teacher, 4l(1), 116-117. https://doi.org/10.1080/0142159X.2018.1500682 